\title{
The First Report of an Intraperitoneal Free-Floating Mass (an Autoamputated Ovary) Causing an Acute Abdomen in a Child
}

\author{
Ibrahim Uygun, Bahattin Aydogdu, Mehmet Hanifi Okur, and Selcuk Otcu \\ Department of Pediatric Surgery and Pediatric Urology, Medical Faculty of Dicle University, 21280 Diyarbakir, Turkey \\ Correspondence should be addressed to Ibrahim Uygun, iuygun@hotmail.com
}

Received 28 July 2012; Accepted 18 September 2012

Academic Editors: M. Gorlitzer and R. Mofidi

Copyright ( $) 2012$ Ibrahim Uygun et al. This is an open access article distributed under the Creative Commons Attribution License, which permits unrestricted use, distribution, and reproduction in any medium, provided the original work is properly cited.

\begin{abstract}
A free-floating intraperitoneal mass is extremely rare, and almost all originate from an ovary. Here, we present the first case with an intraperitoneal free-floating autoamputated ovary that caused an acute abdomen in a child and also review the literature. A 4-year-old girl was admitted with signs and symptoms of acute abdomen. At surgery, the patient had no right ovary and the right tube ended in a thin band that pressed on the terminal ileum causing partial small intestine obstruction and acute abdomen. A calcified mass was found floating in the abdomen and was removed. The pathological examination showed necrotic tissue debris with calcifications. An autoamputated ovary is thought to result from ovarian torsion and is usually detected incidentally. However, it can cause an acute abdomen.
\end{abstract}

\section{Introduction}

An autoamputated ovary $(\mathrm{AO})$ is a very rare cause of an intraabdominal mass [1-25]. The primary pathological event of an $\mathrm{AO}$ is torsion of a normal ovary or an ovarian cyst and the adnexa, followed by infarction and necrosis $[17,21,26$, 27]. Typically, the AO is found incidentally while investigating an unrelated disease, on antenatal ultrasonography, or at surgery [1-25].

Here, we present a patient who underwent surgery for an acute abdomen and was observed to have a free-floating $\mathrm{AO}$ in the abdominal cavity. We also review the occurrence of this extremely rare free-floating mass in children and discuss its diagnosis and management.

\section{Case Presentation}

A 4-year-old girl was admitted with nausea, vomiting, and abdominal pain. On physical examination, the right lower abdominal quadrant was tender. Abdominal guarding and rebound were detected. The abdominal plain X-ray was normal. Emergency ultrasonography (US) showed minimal free fluid. The patient underwent surgery for an acute abdomen. At surgery, a $28 \mathrm{~mm}$ diameter, brown, soft, calcified mass was found floating in the right lower abdomen (Figure 1). The patient had no right ovary and the right tube ended in a thin band that extended to the cecum and pressed on the terminal ileum causing partial small intestine obstruction and acute abdomen (Figure 2). The appendix was hyperemic. The freefloating mass was removed from the abdomen, the right fallopian tube and band were excised, and an appendectomy was performed. The patient was discharged on the second postoperative day. The pathological examination showed long standing necrotic tissue debris with calcifications. The 6-year follow up showed no problems.

\section{Discussion}

A free-floating intraperitoneal mass is extremely rare, and almost all originate from an ovary. To date, there have been only two cases in the literature that originated from other organs $[28,29]$; one such mass in a geriatric woman was from the gallbladder, due to torsion, and caused acute abdomen, while the other was from appendix epiploica, due to torsion, 


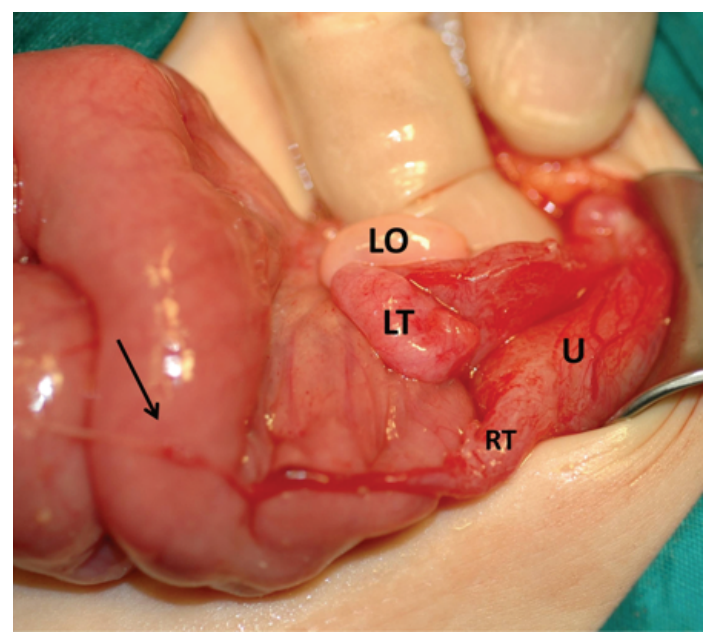

FIGURE 1: The right tube (RT) ended in a thin band (arrow) attached to the cecum and pressed on the terminal ileum. The patient had no right ovary. The left ovary (LO) and tube (LT) and uterus (U) were normal.

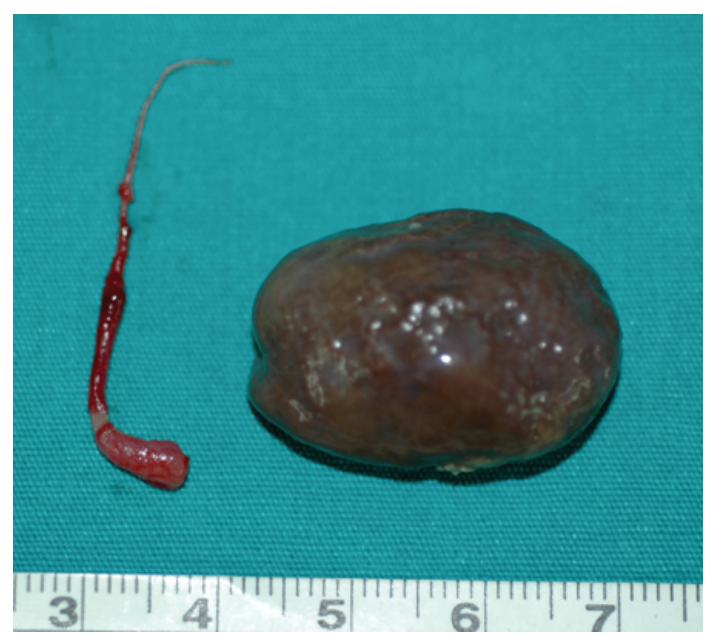

FIGURE 2: The brown, soft, calcified free-floating autoamputated right ovary (right) and the excised right tube ending with a thin band (left).

in a man $[28,29]$. A free-floating intraperitoneal $\mathrm{AO}$ in a child was first reported by Lester and McAlister in 1970 [1]. Our case is the first report of an intraperitoneal free-floating mass causing an acute abdomen in a child.

There have been only 36 reported cases of intraperitoneal free-floating $\mathrm{AO}$ involving children ranging in age from 1 day to 12 years of age, including our case (Table 1) [1-25]. Twenty-five cases were younger than 1 year of age. Although 23 of these infants were diagnosed with a cystic abdominal mass, ranging in diameter from 2.2 to $8 \mathrm{~cm}$ on antenatal US, only 12 of the newborns were operated on during the neonatal period.

Six cases were symptomatic, including our case. One of the newborns had abdominal distention, intestinal obstruction, and respiratory distress syndrome due to an $8 \mathrm{~cm}$ diameter cyst [24]. Four children, ages 14 and 17 months, 2 years, and 12 years, had a history of abdominal pain without an acute abdomen and were diagnosed during routine physical examinations $[1,3,7]$. Only our 4-year-old patient developed an acute abdomen, with signs and symptoms that included tenderness in the right abdominal quadrant, nausea, and vomiting.

Nine of the masses could be palpated on physical examination. Only three cases were diagnosed as an AO preoperatively. Characteristically, an $\mathrm{AO}$ is seen as a free-floating intraabdominal mass on antenatal US [13, 19, 25]. Eight cases were diagnosed incidentally. Two had no abdominal pain but were diagnosed based on palpating an abdominal mass during a routine physical examination [3]. The other six patients were diagnosed with a calcified mass seen on plain X-rays obtained for an unrelated reason [2, 3, 6, 10, 12]. The AO was the right ovary in 17 cases, the left in 11, bilateral in two, and unknown in six cases.

Ultrasonography is safe and sufficient for diagnosing most ovarian cysts and AO. Computed tomography and magnetic resonance imaging may be performed if the mass is complex [22]. In our case, emergency US showed minimal free fluid, but no $\mathrm{AO}$, perhaps because our patient had an 


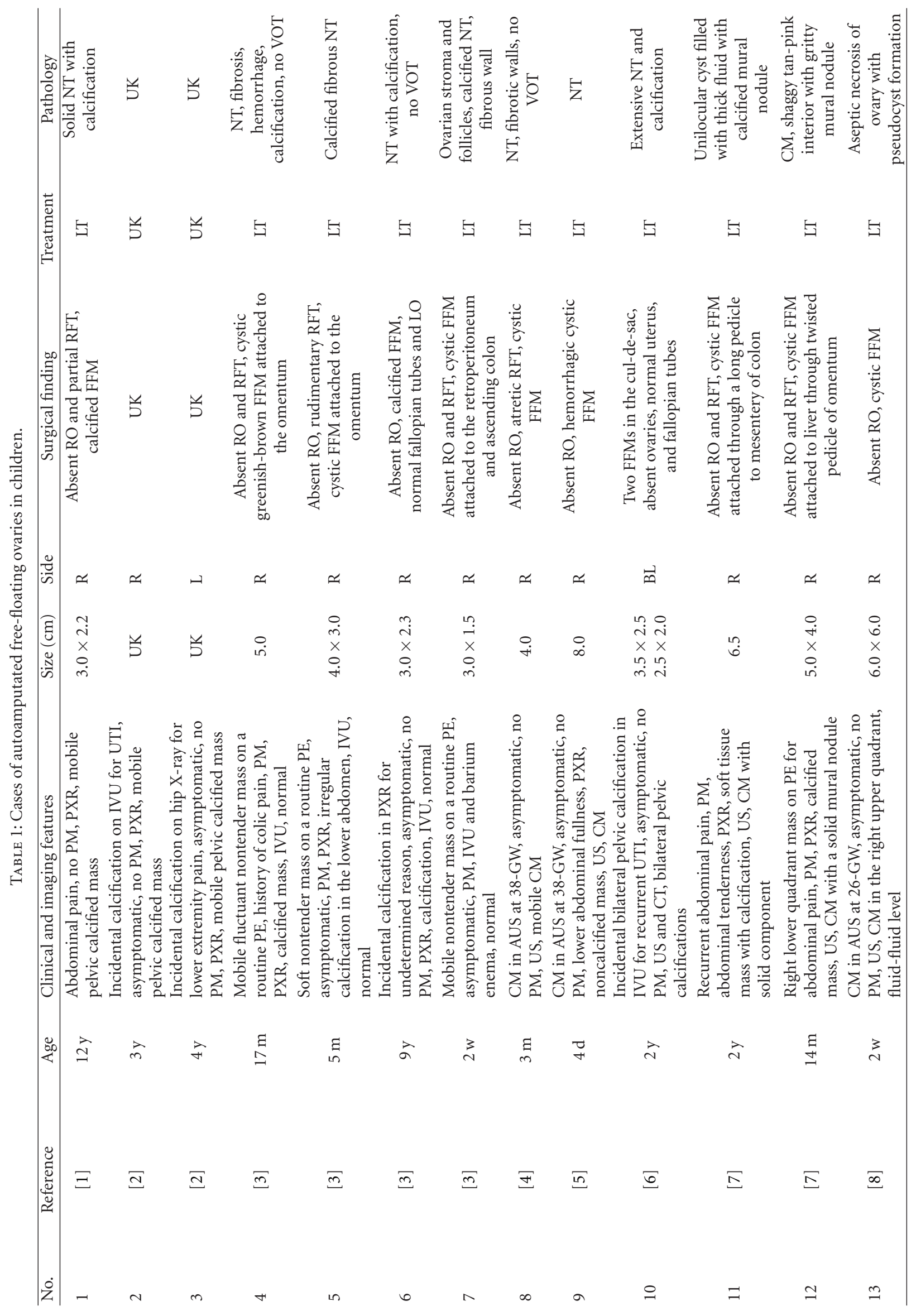




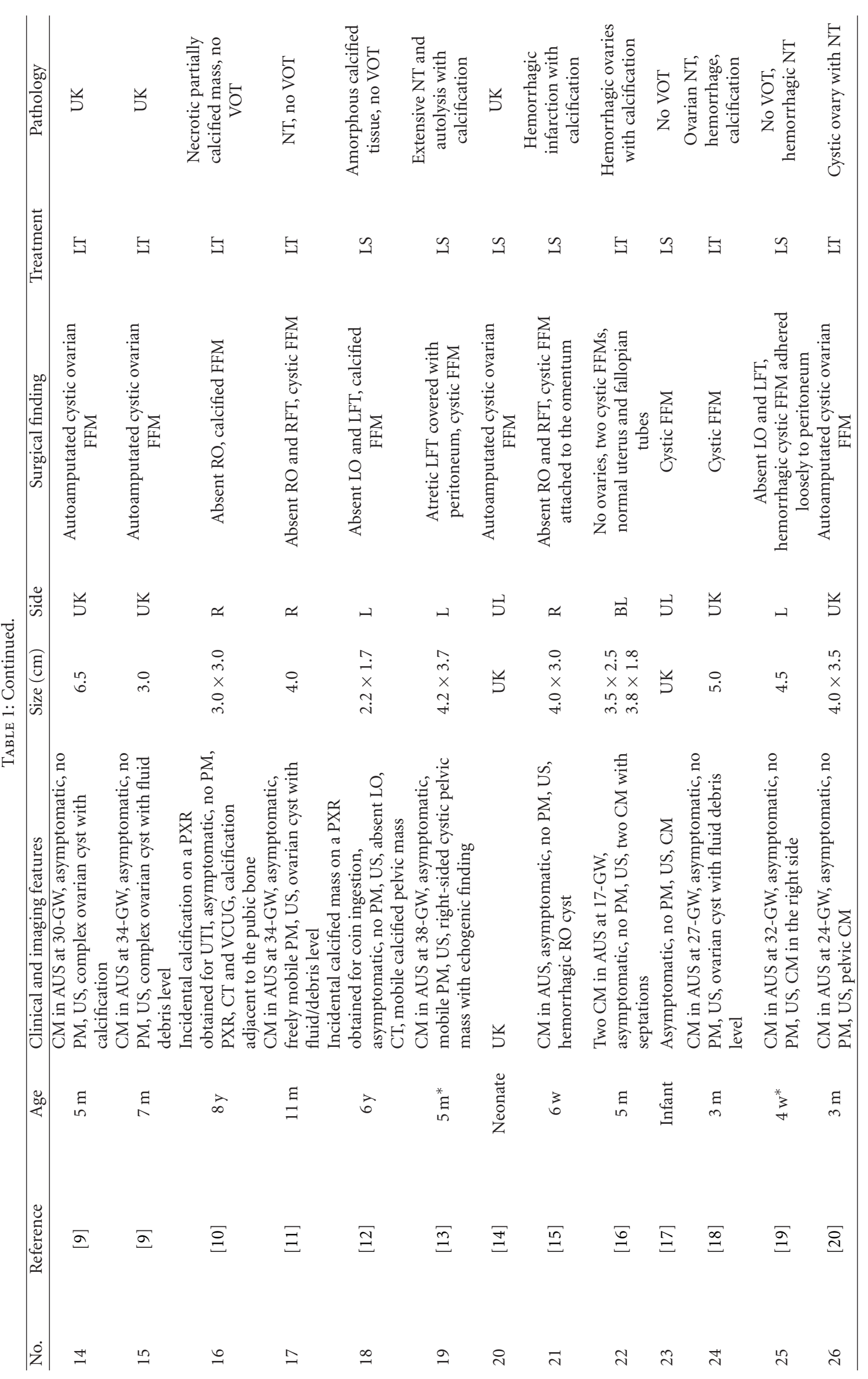




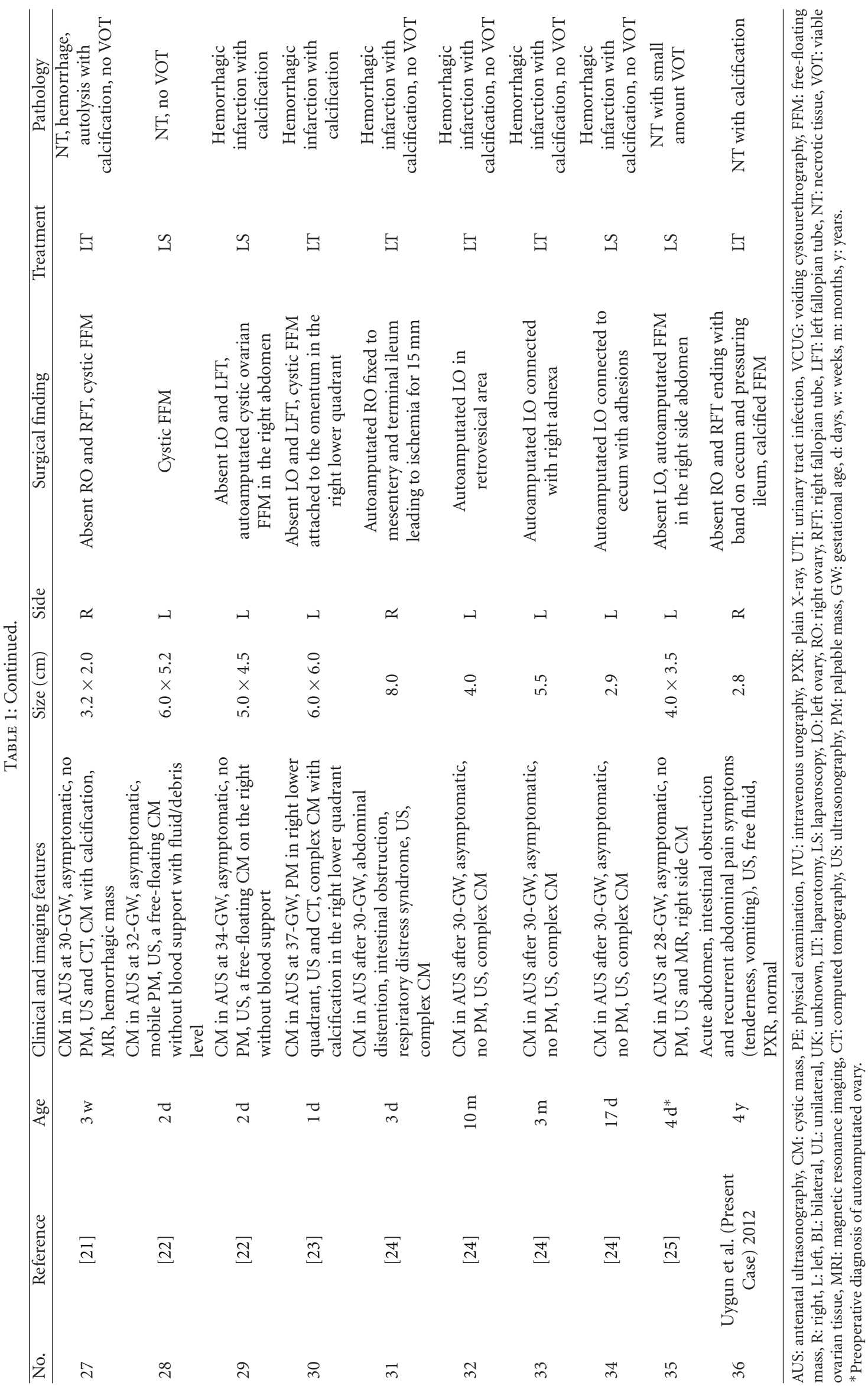


intestinal obstruction and a dilated intestine with intraluminal gas. A plain X-ray may also be sufficient, especially with a calcified AO $[1-3,5,7,10]$. In the literature, 25 of 36 cases of AO were diagnosed prenatally with antenatal US. We believe that this is because antenatal US is performed very commonly worldwide.

Pathologically, necrosis was seen in all cases, and 20 had calcifications. Small amounts of ovarian tissue were seen in seven specimens $[3,7,18,20,23,25]$. In four of these cases, the $\mathrm{AO}$ was attached to the retroperitoneum and ascending colon by vessels [3], the omentum [23], the mesentery of the transverse colon via a long pedicle [7], or to the liver via a hemorrhagic twisted pedicle of omentum [7]. None contained malignant tissue. In adults, Ushakov et al. reported a remarkable characteristic of AO: an AO teratoma became reimplanted as an omental mass in 22 cases of teratoma of the omentum that they reviewed [26]. This adult review and our review of children suggest that an AO may reimplant, develop into omentum or peritoneum, and possibly undergo malignant transformation. Therefore, we suggest that all AOs should be excised instead of taking a wait and see approach.

An $\mathrm{AO}$ is very rare and thought to result from ovarian torsion. Most free-floating AOs are detected incidentally. However, clinicians should remember that it can cause an acute abdomen, and should always make sure there are two ovaries on US in a small child with acute abdomen.

\section{Conflict of Interests}

The authors declare that there is no conflict of interests.

\section{References}

[1] P. D. Lester and W. H. McAlister, "A mobile calcified spontaneously amputated ovary," Journal of the Canadian Association of Radiologists, vol. 21, no. 3, pp. 143-145, 1970.

[2] G. W. Nixon and V. R. Condon, "Amputated ovary: a cause of migratory abdominal calcification," American Journal of Roentgenology, vol. 128, no. 6, pp. 1053-1055, 1977.

[3] L. A. Kennedy, L. E. Pinckney, G. Currarino, and T. P. Votteler, "Amputated calcified ovaries in children," Radiology, vol. 141, no. 1, pp. 83-86, 1981.

[4] E. F. Avni, S. Godart, C. Israel, and C. Schmitz, "Ovarian torsion cyst presenting as a wandering tumor in a newborn: antenatal diagnosis and post natal assessment," Pediatric Radiology, vol. 13, no. 3, pp. 169-171, 1983.

[5] A. Alrabeeah, C. A. Galliani, M. Giacomantonio, S. A. Heifetz, and H. Lau, "Neonatal ovarian torsion: report of three cases and review of the literature," Pediatric Pathology, vol. 8, no. 2, pp. 143-149, 1988.

[6] R. M. Fletcher, D. K. B. Boal, S. R. Karl, and G. W. Gross, "Ovarian torsion: an unusual case of bilateral pelvic calcifications," Pediatric Radiology, vol. 18, no. 2, pp. 172-173, 1988.

[7] G. Currarino and J. C. Rutledge, "Ovarian torsion and amputation resulting in partially calcified, pedunculated cystic mass," Pediatric Radiology, vol. 19, no. 6-7, pp. 395-399, 1989.

[8] J. Mordehai, A. J. Mares, Y. Barki, R. Finaly, and I. Meizner, "Torsion of uterine adnexa in neonates and children: a report of 20 cases," Journal of Pediatric Surgery, vol. 26, no. 10, pp. 1195-1199, 1991.
[9] M. L. Brandt, F. I. Luks, D. Filiatrault, L. Garel, J. G. Desjardins, and S. Youssef, "Surgical indications in antenatally diagnosed ovarian cysts," Journal of Pediatric Surgery, vol. 26, no. 3, pp. 276-282, 1991.

[10] J. Ledesma-Medina, R. B. Towbin, and B. Newman, "Pediatric case of the day. Right ovarian torsion, amputation, and calcification.," Radiographics, vol. 12, no. 1, pp. 199-200, 1992.

[11] A. Aslam, C. Wong, J. M. Haworth, and H. R. Noblett, "Autoamputation of ovarian cyst in an infant," Journal of Pediatric Surgery, vol. 30, no. 11, pp. 1609-1610, 1995.

[12] A. S. Keshtgar and R. R. Turnock, "Wandering calcified ovary in children," Pediatric Surgery International, vol. 12, no. 2-3, pp. 215-216, 1997.

[13] A. J. Jawad, O. Zaghmout, A. D. Al-Muzrakchi, and T. AlHammadi, "Laparoscopic removal of an autoamputated ovarian cyst in an infant," Pediatric Surgery International, vol. 13, no. 2-3, pp. 195-196, 1998.

[14] C. Esposito, V. Garipoli, G. Di Matteo, and M. De Pasquale, "Laparoscopic management of ovarian cysts in newborns," Surgical Endoscopy, vol. 12, no. 9, pp. 1152-1154, 1998.

[15] P. A. Decker, J. Chammas, and T. T. Sato, "Laparoscopic diagnosis and management of ovarian torsion in the newborn.," Journal of the Society of Laparoendoscopic Surgeons, vol. 3, no. 2, pp. 141-143, 1999.

[16] H. J. Corbett and G. A. Lamont, "Bilateral ovarian autoamputation in an infant," Journal of Pediatric Surgery, vol. 37, no. 9, pp. 1359-1360, 2002.

[17] D. Tseng, T. J. Curran, and M. L. Silen, "Minimally invasive management of the prenatally torsed ovarian cyst," Journal of Pediatric Surgery, vol. 37, no. 10, pp. 1467-1469, 2002.

[18] C. Tsobanidou and G. Dermitzakis, "Ovarian cyst as a pelvic mass in an infant," European Journal of Gynaecological Oncology, vol. 24, no. 6, pp. 582-583, 2003.

[19] S. Visnjic, M. Domljan, and B. Zupancic, "Two-port laparoscopic management of an autoamputated ovarian cyst in a newborn," Journal of Minimally Invasive Gynecology, vol. 15, no. 3, pp. 366-369, 2008.

[20] R. J. H. Herrera, L. F. R. Sanchez, R. C. Flores, J. R. Acuna Reyes, and G. Carmona Martínez, "Prenatal diagnosis ovarian cyst with an amputation at three months of age: a case report," Ginecologia y Obstetricia de Mexico, vol. 77, no. 8, pp. 372-375, 2009.

[21] Y. Koike, M. Inoue, K. Uchida et al., "Ovarian autoamputation in a neonate: a case report with literature review," Pediatric Surgery International, vol. 25, no. 7, pp. 655-658, 2009.

[22] N. Zampieri, G. Scirè, C. Zamboni, A. Ottolenghi, and F. S. Camoglio, "Unusual presentation of antenatal ovarian torsion: free-floating abdominal cysts. Our experience and surgical management," Journal of Laparoendoscopic and Advanced Surgical Techniques, vol. 19, no. 1, pp. S149-S152, 2009.

[23] J. Amodio, A. Hannao, E. Rudman, F. Banfro, and E. Garrow, "Complex left fetal ovarian cyst with subsequent autoamputation and migration into the right lower quadrant in a neonate: case report and review of the literature," Journal of Ultrasound in Medicine, vol. 29, no. 3, pp. 497-500, 2010.

[24] S. Marinkovic, R. Jokic, S. Bukarica, A. N. Mikic, N. Vuckovic, and J. Antic, "Surgical treatment of neonatal ovarian cysts," Medicinski Pregled, vol. 64, no. 7-8, pp. 408-412, 2011.

[25] T. Kuwata, S. Matsubara, and K. Maeda, "Autoamputation of fetal/neonatal ovarian tumor suspected by a "side change" of the tumor," Journal of Reproductive Medicine for the Obstetrician and Gynecologist, vol. 56, no. 1-2, pp. 91-92, 2011.

[26] F. B. Ushakov, D. Meirow, D. Prus, E. Libson, A. BenShushan, and N. Rojansky, "Parasitic ovarian dermoid tumor of the 
omentum-a review of the literature and report of two new cases," European Journal of Obstetrics Gynecology and Reproductive Biology, vol. 81, no. 1, pp. 77-82, 1998.

[27] S. Schmahmann and J. O. Haller, "Neonatal ovarian cysts: pathogenesis, diagnosis and management," Pediatric Radiology, vol. 27, no. 2, pp. 101-105, 1997.

[28] F. J. Laso, C. Procel, I. Pastor, G. Vásquez, and R. M. Ramos, "Gallbladder torsion: report of a case," Anales de Medicina Interna, vol. 6, no. 3, pp. 149-150, 1989.

[29] F. J. L. Murat and M. T. Gettman, "Free-floating organized fat necrosis: rare presentation of pelvic mass managed with laparoscopic techniques," Urology, vol. 63, no. 1, pp. 176-177, 2004. 


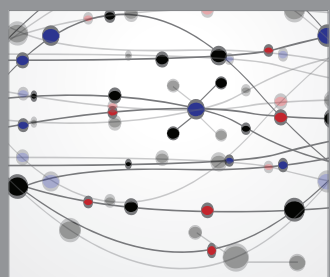

The Scientific World Journal
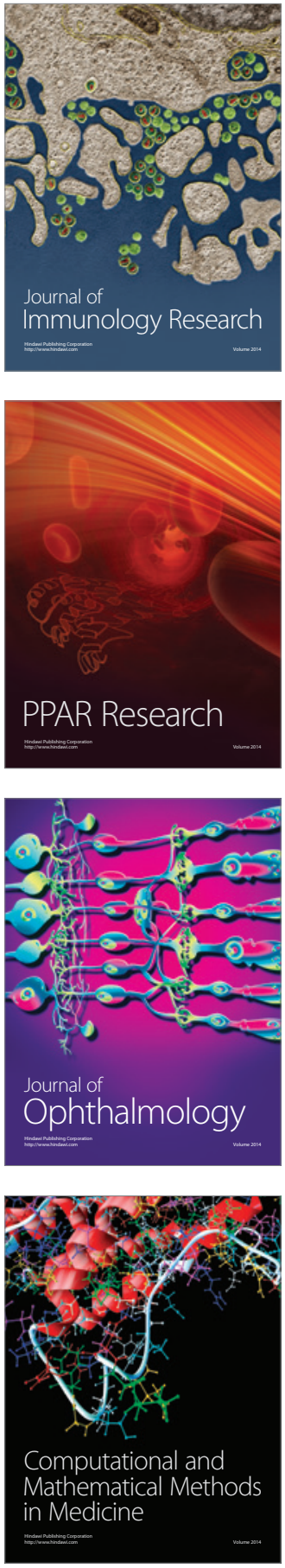

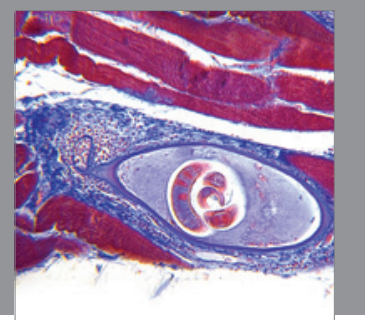

Gastroenterology

Research and Practice
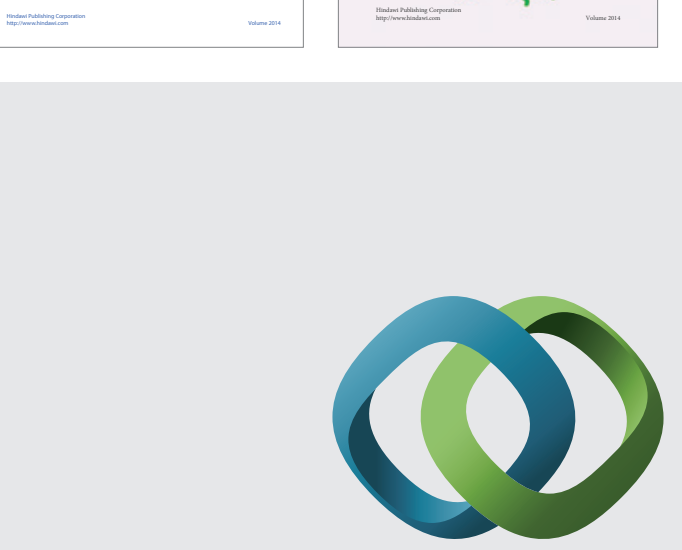

\section{Hindawi}

Submit your manuscripts at

http://www.hindawi.com
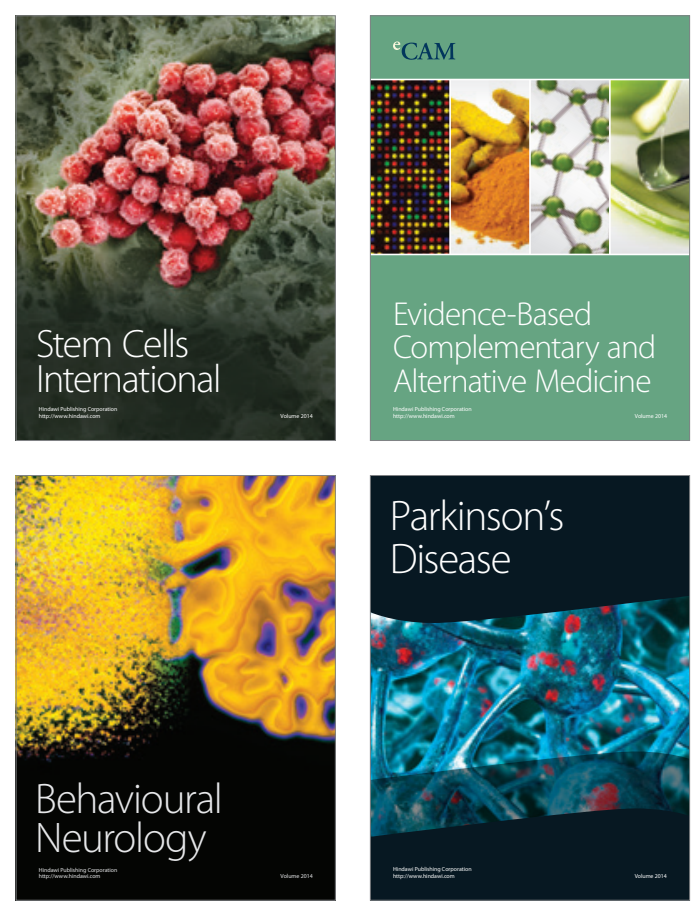

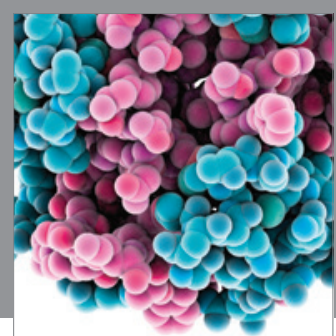

Journal of
Diabetes Research

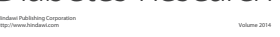

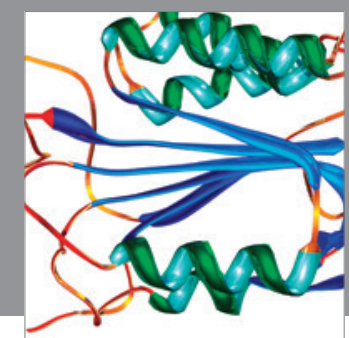

Disease Markers
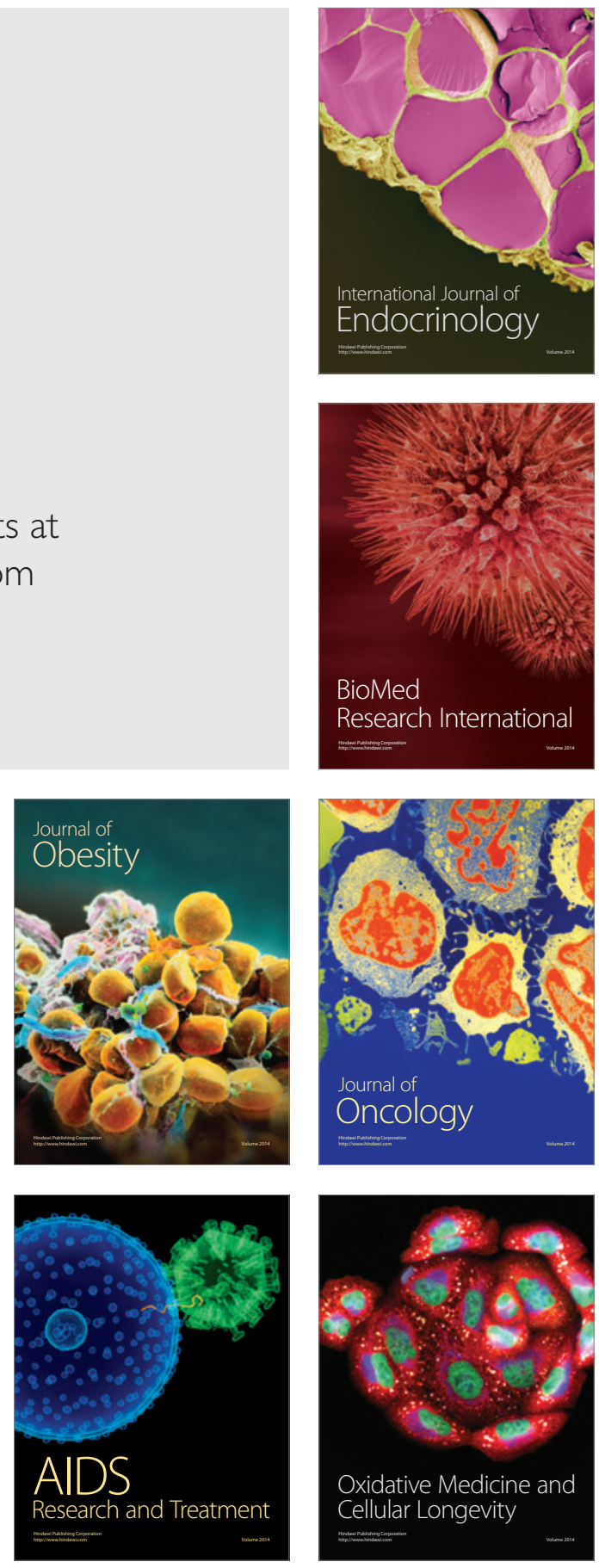